\title{
LAS MARCAS OLFATIVAS EN COLOMBIA
}

DANIEL BARRIOS ESPINOSA*

\section{INTRODUCCIÓN}

Quienes ofrecen bienes y servicios en el mercado están en la constante búsqueda de diferentes métodos que les permitan obtener la mayor porción posible de la demanda. En esto, las marcas juegan un papel fundamental para la formación de una clientela que identifique los productos y los diferencie de otros similares. Cada vez hay más innovación en este campo, y el derecho marcario se ha ido adaptando para ampliar su espectro y proteger todas las marcas.

Así han surgido los nuevos tipos de marcas, entre ellas la olfativa. Para que, desde el ordenamiento jurídico, se le puede garantizar al comerciante el uso exclusivo del signo distintivo, estas marcas necesitan que efectivamente se realice el registro ante la autoridad competente. Ante estos indetenibles procesos de transformación a nivel mundial en el derecho marcario, los signos olfativos representan un tema de estudio en el que se necesita ahondar. Tal necesidad proviene de la falta de claridad que hay en cuanto a la posibilidad de registrar marcas olfativas en Colombia.

Por eso, el presente documento de investigación tiene como objetivo analizar el desarrollo del registro de las marcas olfativas en Colombia. Esto se realizará por medio de una revisión bibliográfica de casos relevantes en la jurisprudencia colombiana, reglamentación vigente, autoridades de propiedad industrial con potestad reglamentaria, entidades multilaterales, jurisprudencia y doctrina.

Se intentará demostrar las dificultades que existen para el registro de las marcas olfativas en el mundo y específicamente en Colombia. Para tal fin, se explicará la noción de marca y en qué consisten sus tres características (perceptibilidad, distintividad y representación gráfica); se recogerán opiniones de la doctrina sobre

\footnotetext{
* Abogado de la Pontificia Universidad Javeriana, Bogotá. Bogotá, D. C., Colombia. Correo electrónico: daniellbarrios@hotmail.com. Fecha de recepción: 24 de agosto de 2017. Fecha de aceptación: 31 de octubre de 2017. Para citar el artículo: Barrios Espinosa, J. "Las marcas olfativas en Colombia", Revista La Propiedad Inmaterial n.o 24, Universidad Externado de Colombia, julio-diciembre 2017, pp. 95-127. DoI: https://doi. org/10.18601/16571959.n24.05
} 
la importancia y función de las marcas en la dinámica comercial y el papel de los olores en su evolución, y se analizará la importancia del registro del signo distintivo y su procedimiento en Colombia.

Luego, por medio de la ilustración de casos de registros de diferentes marcas a nivel nacional e internacional, se explicará qué son las marcas tradicionales. Posteriormente, se verá en qué consiste una marca olfativa y cómo esta se puede adaptar para cumplir las características de perceptibilidad, distintividad y representación gráfica.

Con el fin de contextualizar y aproximarse a la situación en Colombia, se hará una breve exposición del estado del arte de las marcas de olor en Estados Unidos y Europa. Finalmente, se verá cuál es la regulación vigente y aplicable a las marcas olfativas en el país y se hará una revisión de los casos relevantes, para llegar a unas conclusiones.

\section{GENERALIDADES}

\section{I Noción}

"Una marca es cualquier signo que sea apto para distinguir productos y servicios en el mercado y que, además, sea susceptible de representarse gráficamente (art. 134, D. 486)"1. Esta definición establece entonces que las marcas tienen tres características: signo perceptible, distintividad y representación gráfica.

\subsubsection{Perceptibilidad}

Es pertinente desglosar estas características desprendidas de la definición y explicar primero en qué consiste la expresión "cualquier signo". Quiere decir que todo signo que sea susceptible de ser aprehendido por los sentidos y asimilado por la inteligencia puede llegar a ser una marca. La norma citada prevé posibilidades de signos que sean perceptibles tanto por la visión como por la audición, el olfato, el gusto y el tacto.

La doctrina ha afirmado que "percibir es apreciar algo por medio de los sentidos o de la inteligencia. Y perceptible es, entonces, lo que se puede percibir"2.

\subsubsection{Distintividad}

La distintividad es explicada por el Tribunal de Justicia de la Comunidad Andina así:

1 Varela Pezzano, Eduardo. Manual de propiedad intelectual. Bogotá: Asociación Cavelier del Derecho, 2015.

2 Pachón, Manuel y Sánchez Ávila, Zoraida. El Régimen Andino de la Propiedad Industrial. Bogotá: Ediciones Jurídicas Gustavo Ibáñez, 1995. 
[...] la capacidad que tiene un signo para individualizar, identificar y diferenciar en el mercado los productos o servicios, haciendo posible que el consumidor o usuario los seleccione. Es considerada como característica esencial que debe reunir todo signo para ser registrado como marca y constituye el presupuesto indispensable para que esta cumpla su función principal de identificar e indicar el origen empresarial $y$, en su caso, incluso la calidad del producto o servicio, sin riesgo de confusión o asociación... ${ }^{3}$.

Por su parte, el entonces Tribunal de Justicia de las Comunidades Europeas, hoy Tribunal de Justicia de la Unión Europea, hizo énfasis en que "el carácter distintivo de una marca [...] debe apreciarse en relación con los productos o servicios para los que se solicita [su] registro"'4.

[Con base en] la distintividad se protege al empresario o productor, para que sus bienes o servicios sean claramente distinguidos en el mercado, y al consumidor, quien al diferenciar una marca de otra evita la confusión, el error o el engaño que puede aparecer cuando entre dos signos no exista una evidente distintividad tanto en los signos en sí mismos como entre estos y los productos que la marca protege ${ }^{5}$.

Los nombres genéricos o comunes no constituyen un signo distintivo, puesto que no individualizan el producto al referirse a la naturaleza de este. Dicho de otra manera, la palabra no puede describir lo que se protege con la marca, por ejemplo, la marca "relojes" para vender relojes. De igual manera, la distinción debe ser en el mercado específico en el que se ofrecen los productos y servicios, ya que pueden coexistir marcas iguales o similares registradas a nombre de distintos titulares, siempre que distingan productos o servicios diferentes. Por ejemplo, el logotipo de una manzana junto a la palabra Apple como una marca de productos electrónicos y otra como una empresa titular de los derechos de la música de The Beatles.

Es esta característica de distintividad la que tiene un valor económico, ya que es la que ayuda a crear un good will en los productos y servicios y la que tiene el potencial de atraer clientela ${ }^{6}$.

\subsubsection{Representación gráfica}

La representación gráfica del signo distintivo es de suma importancia para la solicitud del registro ante la autoridad competente, que en Colombia es la Superinten-

3 Tribunal de Justicia de la Comunidad Andina. Proceso 15-IP. 27 de abril de 2011.

4 Tribunal de Justicia de la Unión Europea (tJue]). Philips v. Remington, C-299/99. 18 de junio de 2002.

5 Tribunal de Justicia de la Comunidad Andina. Proceso 28-IP-96. 31 de octubre de 1997.

6 Lizarazu Montoya, Rodolfo. Manual de propiedad industrial. Bogotá: Legis Editores, 2014, p. 27. ISBN: 978-958-767-217-6. 
dencia de Industria y Comercio (sIc). Tiene como finalidad la publicidad, ya que así cualquier persona puede saber en qué consiste la marca y oponerse en caso de que considere que tiene un signo igual o similar. Consiste en una representación idónea que describa con fidelidad el signo que se pretende registrar como marca por medio de recursos gráficos que se manifiesten visualmente. Las condiciones de representación gráfica varían para cada tipo de marca, como se verá más adelante, cuando se expliquen brevemente las clases de marca que existen. El tipo de marca objeto de este artículo encuentra en este requisito su mayor dificultad. No hay unificación de criterios sobre cuál es la manera adecuada de representarlo gráficamente, lo que ha hecho que pocas personas hayan logrado registrar una marca olfativa en el mundo.

El jurista español Dámaso Ruiz-Jarabo Colomer definió la representación gráfica así:

Describir algo usando símbolos susceptibles de ser dibujados. Quiere esto decir que a la aptitud originaria de un signo cualquiera para distinguir debe añadirse su capacidad para ser 'llevado al papel' y, por consiguiente, para ser visualmente percibido. Y como quiera que se trata de discriminar, esa representación debe hacerse de manera que sea comprensible, porque la comprensión es presupuesto del discernimiento 7 .

\subsection{FunCión}

Con el fin de dejar clara la importancia de las marcas comerciales y su registro y, por ende, la de realizar una investigación de la situación y problemática de las marcas olfativas, se procederá a enunciar y explicar las funciones que tienen las marcas en general para un comerciante. Una marca cumple tres funciones: 1) distingue los productos de los productos de los competidores, 2) es garantía de consistencia y calidad y 3) ayuda a publicitar el producto.

Sobre la importancia de las funciones que cumplen las marcas en el comercio, la Corte Suprema de Justicia de los Estados Unidos ha dicho en la sentencia de 1942 que:

Si bien es cierto que vivimos a base de símbolos, no lo es menos que compramos mercancías por razón de ellos. Una marca comercial es el atajo por el cual se conduce al comprador a escoger lo que desea, o lo que se le ha hecho creer que desea. El propietario de una marca explota esta propensión humana haciendo todo esfuerzo posible por impregnar la atmósfera del mercado con el poder de atracción de un símbolo agradable. Sean cuales fueren los medios que se empleen, el propósito al final es el mismo: llevar, a través de la marca, a la mente del comprador potencial el deseo de adquirir el

7 Ruiz-Jarabo Colomer, Damaso. Conclusiones sobre el Asunto C-273/00. 6 de noviembre de 2001 . 
artículo en que ella aparece. Una vez que ha logrado esto, el propietario de la marca tiene en sus manos algo valioso ${ }^{8}$.

La principal función de una marca es identificar los productos de un comerciante y distinguirlos de los productos de sus competidores. Sin embargo, la marca cumple más funciones. En palabras del jurista Rodolfo Lizarazu, una marca:

[... cumple varias funciones en el mercado: individualiza un producto o servicio respecto a otros de su misma categoría o de la competencia, identifica el origen de los bienes y servicios y de las empresas o comerciantes que los producen o prestan, permite asociar los productos y servicios con una cierta calidad y, de esa forma, ofrecer una garantía para los demás comerciantes, constituye un elemento esencial para publicitar las mercaderías y servicios a los cuales se le vincula y para atraer clientela, confronta a los productores de bienes y servicios que los comercializan y, para finalizar, protege tanto al titular del registro frente a terceros que quieran aprovecharse del signo distintivo como al consumidor, porque le asegura a este último el producto que desea adquirir e identifica al comerciante ante cualquier reclamación que haga el usuario?.

Sobre la última función, ayudar a publicitar el producto, una guía que hizo la Asociación de Marcas de los Estados Unidos para los hombres de negocios dice que "la marca que [un comerciante] escoja debe actuar como un buen vendedor. Debe ser un símbolo simpático, con suficiente poder de atracción para persuadir al comprador de lo deseable que es el producto en que ella aparece" 10 .

\subsection{Registro}

\subsubsection{Importancia}

Al ser las marcas uno de los bienes más significativos de las empresas y uno de los instrumentos más importantes en todo el proceso de mercadeo y comercialización de los bienes y servicios que ofrecen, es importante la protección que el ordenamiento jurídico les puede brindar.

La adquisición del derecho marcario se hace mediante el registro de la marca, y quien sea titular de este será el beneficiario de la protección mencionada. Así lo establece el artículo 154 de la Decisión 486 de la CAN al decir que "el derecho al

8 Supreme Court of the United States (scotus). Mishawaka Rubber \& Woolen Mfg. Co. v. S. S. Kresge Co., 316 U.S. 203. 5 de mayo de 1942.

9 Lizarazu Montoya. Op. cit., p. 41.

10 The United States Trademark Association (USTA). El manejo de las marcas comerciales, una guía para el hombre de negocios [Traducido del inglés por Brigard y Urrutia]. Nueva York: Ediciones Tercer Mundo, 1965. 
uso exclusivo de una marca se adquirirá por el registro de [esta] ante la respectiva oficina nacional competente" 11 .

En palabras de Eduardo Varela, "el derecho al uso exclusivo de las marcas implica la facultad de impedir que otras personas realicen actos en el comercio con ellas sin la autorización de su titular, y se adquiere registrándolas ante la Oficina Nacional de Propiedad Industrial"12.

De manera amplia, la mencionada decisión de la Comunidad Andina, en su artículo 155, impide a aquellos terceros que no sean titulares de la marca utilizarla.

Artículo 155.- El registro de una marca confiere a su titular el derecho de impedir a cualquier tercero realizar, sin su consentimiento, los siguientes actos:

a) aplicar o colocar la marca o un signo distintivo idéntico o semejante sobre productos para los cuales se ha registrado la marca; sobre productos vinculados a los servicios para los cuales esta se ha registrado; o sobre los envases, envolturas, embalajes o acondicionamientos de tales productos;

b) suprimir o modificar la marca con fines comerciales después de que se hubiese aplicado o colocado sobre los productos para los cuales se ha registrado la marca; sobre los productos vinculados a los servicios para los cuales esta se ha registrado; o sobre los envases, envolturas, embalajes o acondicionamientos de tales productos;

c) fabricar etiquetas, envases, envolturas, embalajes u otros materiales que reproduzcan o contengan la marca, así como comercializar o detentar tales materiales;

d) usar en el comercio un signo idéntico o similar a la marca respecto de cualesquiera productos o servicios, cuando tal uso pudiese causar confusión o un riesgo de asociación con el titular del registro. Tratándose del uso de un signo idéntico para productos o servicios idénticos, se presumirá que existe riesgo de confusión;

e) usar en el comercio un signo idéntico o similar a una marca notoriamente conocida respecto de cualesquiera productos o servicios, cuando ello pudiese causar al titular del registro un daño económico o comercial injusto por razón de una dilución de la fuerza distintiva o del valor comercial o publicitario de la marca, o por razón de un aprovechamiento injusto del prestigio de la marca o de su titular;

f) usar públicamente un signo idéntico o similar a una marca notoriamente conocida, aun para fines no comerciales, cuando ello pudiese causar una dilución de la fuerza

11 Comunidad Andina de Naciones (CAN). Decisión 486: Régimen Común sobre Propiedad Industrial. 14 de septiembre de 2000.

12 Varela Pezzano. Op. cit., p. 23. 
distintiva o del valor comercial o publicitario de la marca, o un aprovechamiento injusto de su prestigio.

Los dos artículos siguientes también conllevan derechos que se derivan del registro de la marca.

Artículo 161.- Un registro de marca concedido o en trámite de registro podrá ser transferido por acto entre vivos o por vía sucesoria, con o sin la empresa a la cual pertenece. $[\ldots]$

Artículo 162.- El titular de una marca registrada o en trámite de registro podrá dar licencia a uno o más terceros para la explotación de la marca respectiva.

Queda ilustrada entonces la importancia del registro de una marca, tanto en el ámbito jurídico como en el económico.

\subsubsection{Procedimiento}

El procedimiento para el registro de una marca en Colombia se adelanta ante la Superintendencia de Industria y Comercio (sIC), y los pasos que se deben seguir son los siguientes.

\section{Solicitud}

Es una petición ante la sic que debe cumplir los requisitos del artículo 138 de la Decisión 486 de 2000 de la CAN. Aquí se tienen que incluir la representación gráfica del signo y otros requisitos formales, como el petitorio (formato con el nombre del solicitante, datos de contacto, identificación, la clase en la que se pretende registrar la marca, etc.) y otros más ${ }^{13}$.

Aquí también se debe ubicar el producto o servicio de la marca que se quiere registrar en una o varias categorías de la Clasificación Internacional de Niza, que es un tratado multilateral que tiene como propósito la clasificación internacional de productos y servicios para el registro de marcas. El objetivo de la clasificación es especificar en qué mercado específico se va a utilizar el producto o servicio, de tal manera que tenga el monopolio de la marca sobre ese ámbito ${ }^{14}$. Este criterio de especificidad es el que permite la coexistencia de marcas, como en el ejemplo explicado anteriormente, en el que es posible que exista el logotipo de una manzana junto a la palabra Apple registrada como una marca de productos electrónicos y otra como una empresa titular de los derechos de la música de The Beatles. 


\section{Presentación de la solicitud}

Se radican el formulario de petición y sus anexos ante la sic, y si se cumplen los requisitos legales, se asigna una fecha de presentación, que será la fecha de recepción de los documentos. Esto es importante, porque garantiza al titular que, si se le confiere, su derecho prima sobre otro presentado posteriormente. La excepción a esto ocurre en los casos de las marcas que hayan "distinguido productos o servicios en una exposición reconocida oficialmente y realizada en cualquier país, siempre que sea solicitada dentro de los seis meses contados a partir del día en que tales productos o servicios se exhibieran por primera vez con dicha marca. En ese caso se podrá tener por presentada la solicitud desde la fecha de exhibición"15. La presentación de la solicitud se puede hacer de manera presencial o en línea, a través de la plataforma de la Superintendencia de Industria y Comercio ${ }^{16}$.

\section{Examen de forma}

La SIC analiza, dentro de los siguientes 15 días hábiles a la presentación de la solicitud, si esta cumple los requisitos de forma que indican los artículos 138 y 139 de la Decisión 486. Si cumple todos los requisitos, se ordena la publicación en la Gaceta de la Propiedad Industrial ${ }^{17}$.

\section{Publicación}

La solicitud se publica en la Gaceta de la Propiedad Industrial. Esta es "un medio de información oficial de la sic mediante el cual se dan a conocer las solicitudes presentadas y [los] títulos otorgados en relación con marca y demás signos distintivos, patentes de invención, modelos de utilidad y diseños industriales"18. A la gaceta puede acceder cualquier persona del mundo a través de la página de Internet de la sic.

\section{Oposición}

Una vez publicada la solicitud de la marca en la Gaceta de la Propiedad Industrial, quien tenga interés legítimo puede oponerse al registro dentro de los 30 días hábiles siguientes. El fin de esto es que a aquellos que consideren que tienen una marca idéntica o similar no se les viole el monopolio que tienen sobre su marca. El solicitante tiene 30 días hábiles para controvertir la oposición. En esta etapa puede haber una audiencia de facilitación ante la sic para resolver la controversia.

15 Comunidad Andina de Naciones. Op. cit., art. 141.

16 Lizarazu Montoya. Op. cit., pp. 58-67.

17 Idem., pp. 58-67.

18 Superintendencia de Industria y Comercio (sIc). [Página web] Disponible en http:// www.sic.gov.co/gaceta-oficial-de-la-propiedad-industrial [Consultado en 2017] 


\section{Examen de fondo y decisión}

Aquí la autoridad administrativa decide sobre la concesión o denegación de la marca mediante una resolución. Si es concedida, expide un registro. La decisión es susceptible de recurso de apelación. En el examen de fondo se mira la registrabilidad de la marca, si se cumplen los requisitos de distintividad y representación gráfica, y se analizan los argumentos de la oposición, si se presentó alguna ${ }^{19}$.

Antes la sic no tenía un término para tomar una decisión. Sin embargo, desde la expedición de la Ley 1437 de 2011 (Código de Procedimiento Administrativo y de lo Contencioso Administrativo), en virtud del numeral 4 del artículo 91, el solicitante puede pedirle a la entidad que se demore máximo seis meses en conceder o negar el registro, esto sin perjuicio de las oposiciones que se presenten.

El plazo de seis meses corresponde a la posibilidad de que se reivindique la prioridad de una marca. Esta es:

una ficción legal que le permite al solicitante de una marca en cualquiera de los Estados miembros del Convenio de París hacer valer la fecha de presentación de su solicitud en otro u otros Estados miembros, presentando la marca dentro de los 6 meses siguientes a la fecha original de solicitud. De esta manera, la marca se considera presentada con anterioridad a todas aquellas que se hubiesen solicitado en ese lapso, con lo cual se le otorga a su solicitante el derecho a turno para la concesión de su marca ${ }^{20}$.

\section{MARCAS NO TRADICIONALES}

Las marcas tradicionales son las que se expresan por medio de letras, números, palabras, dibujos o símbolos, y tienen principalmente aspectos visuales y fonéticos. Entonces, las marcas no tradicionales son aquellas percibidas por cualquiera de los cinco sentidos (las visuales y las de sonidos, olores, sabores y texturas) y cuya representación debe ser hecha por medio de métodos de representación no tradicionales ${ }^{21}$.

Se explicarán a continuación las marcas no tradicionales mediante ejemplos, con el fin de contextualizar las marcas olfativas entre estas. A partir de la distintividad y la representación, se verá cuál es la complejidad que algunas encuentran para el registro, ya que no suelen tener la capacidad inherente de ser distintivas y requieren de otras condiciones para adquirir un carácter distintivo. Por otro lado, para cumplir el requisito de representación gráfica es necesario un mayor esfuerzo y

19 Lizarazu Montoya. Op. cit., pp. 58-67.

20 Superintendencia de Industria y Comercio (sIc). Superintendencia concederá marcas en 4 meses [en línea]. 28 de agosto de 2014. Disponible en http://www.sic.gov.co/noticia/ superindustria-concedera-marcas-en-4-meses

21 Castro García, Juan David. Las marcas no tradicionales. Revista La Propiedad Inmaterial. Bogotá: Universidad Externado de Colombia, 2012, (16), pp. 297-325. IssN: 1657-1959. 
creatividad por parte de quien pretende registrarla, en comparación con las marcas tradicionales. Entre este tipo de marcas se encuentran las siguientes:

\section{I MarCas tRIDIMENSIONALES}

Consisten en las formas no usuales de los productos, en los envases, los envoltorios o la presentación del producto.

\section{Distintividad}

La falta de esta característica es la principal razón por la que son negadas las solicitudes de registro de marcas tridimensionales. Sectores de la doctrina han afirmado lo siguiente:

La mayor parte de las solicitudes son rechazadas por falta de carácter distintivo, obstáculo que pocos solicitantes han superado. Quienes lo han logrado, han registrado marcas que tienen un carácter distintivo extraordinariamente acentuado o que han venido siendo usadas ampliamente y durante largo tiempo, por lo que han adquirido un carácter distintivo claro en el mercado ${ }^{22}$.

Su dificultad entonces consiste en que la distintividad sea extraordinariamente notoria.

\section{Representación gráfica}

Suele hacerse mediante imágenes o dibujos que muestren, desde diferentes ángulos y perspectivas, el carácter tridimensional.

\section{EJEMPLOS DE MARCAS TRIDIMENSIONALES}

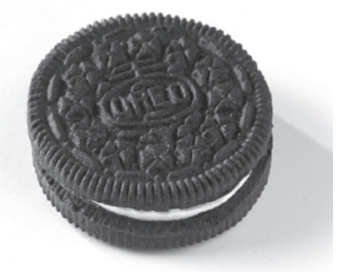

Marca: Tapa de Galletas Oreo

Registro EuIPo n. ${ }^{\circ} 8566176$

Territorio: Unión Europea

Clasificación Niza: 30

Fuente: https://euipo.europa.eu/eSearch/\#details/trademarks/008566176

22 Soutol, Frank y Bresson, Jean-Philippe. Las marcas tridimencionales en la práctica francesa y comunitaria. Revista de la OMPI. Ginebra: OMPI (febrero de 2009). ISSN: 1020-7082. 
Marca: Empaque de Chocolate Toblerone

Registro EuIPo n. ${ }^{\circ} 31203$

Territorio: Unión Europea

Clasificación Niza: 30

Fuente: https://euipo.europa.eu/eSearch/\#details/trademarks/000031203
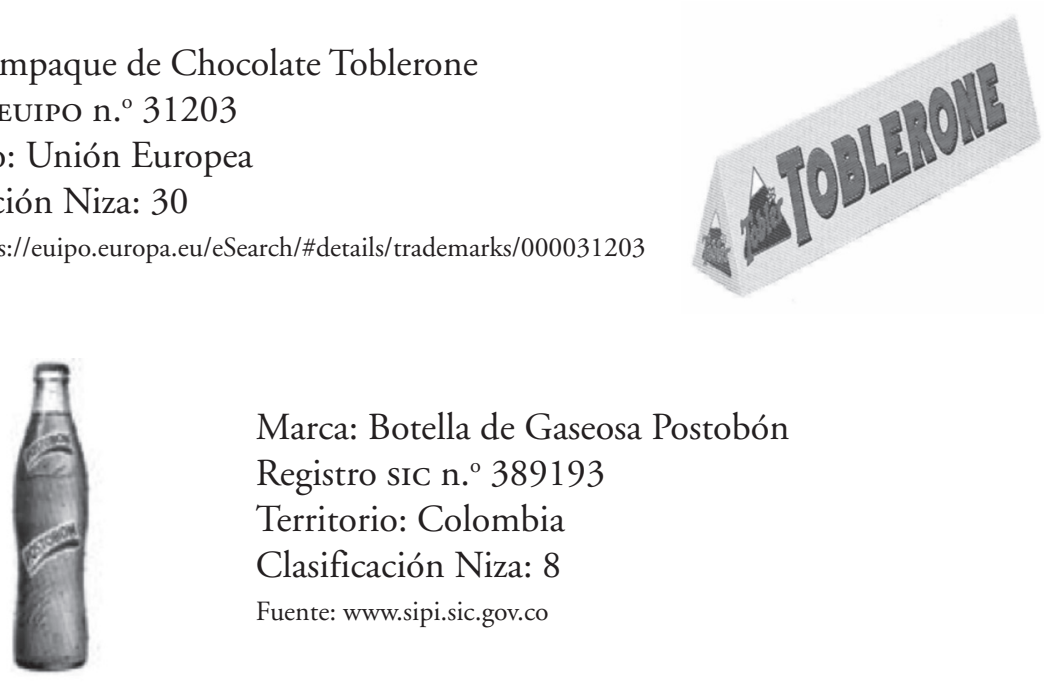

Marca: Botella de Gaseosa Postobón

Registro sIC n. ${ }^{\circ} 389193$

Territorio: Colombia

Clasificación Niza: 8

Fuente: www.sipi.sic.gov.co

\subsection{Marcas SONORAS}

Están integradas por un sonido o un jingle.

\section{Distintividad}

$\mathrm{Al}$ respecto, el Comité Permanente sobre el Derecho de Marcas, Diseños Industriales e Indicaciones Geográficas de la Organización Mundial de la Propiedad Intelectual (scT de la OMPI), en su decimosexta sesión afirmó:

Si bien no puede descartarse la posibilidad de que los sonidos tengan una capacidad intrínseca para distinguir bienes y servicios, posiblemente es más frecuente que adquieran su carácter distintivo con el uso y que se empleen en combinación con otros tipos de marcas, tales como las marcas verbales o figurativas. En tal caso, ambos tipos de signos deben ser capaces de operar como marcas. ${ }^{23}$

Su dificultad radica en que no son intrínsecamente distintivos, sino que adquieren tal distintividad mediante el uso y su empleo en combinación con otros tipos de marcas.

23 sст de la ompi. Nuevos tipos de marcas. En Comité Permanente sobre el Derecho de Marcas, Diseños Industriales e Indicaciones Geográficas. Decimosexta sesión. Ginebra: OMPI, 2006. 
Representación gráfica

Consiste en un pentagrama acompañado de un archivo de sonido.

\section{EJEMPLOS DE MARCAS SONORAS}

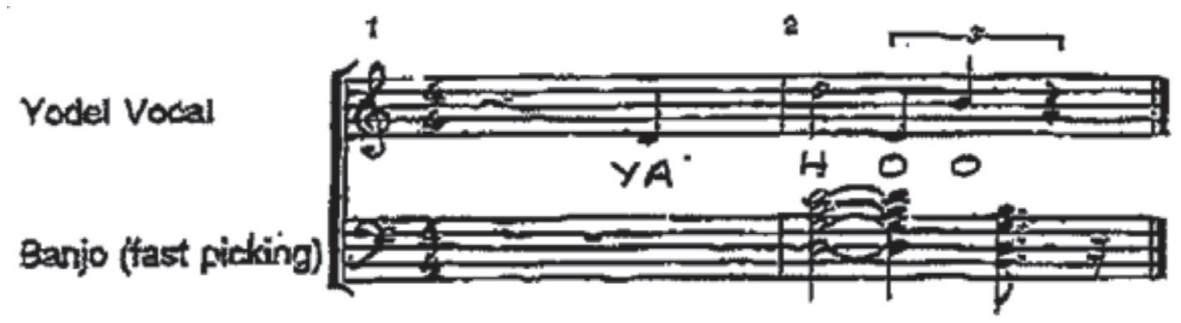

Marca: Sonido Yahoo

Registro Euipo n. ${ }^{\circ} 1772086$

Clasificación Niza: 35, 38, 42.

Territorio: Unión Europea

Fuente: https://euipo.europa.eu/eSearch/\#details/trademarks/001772086
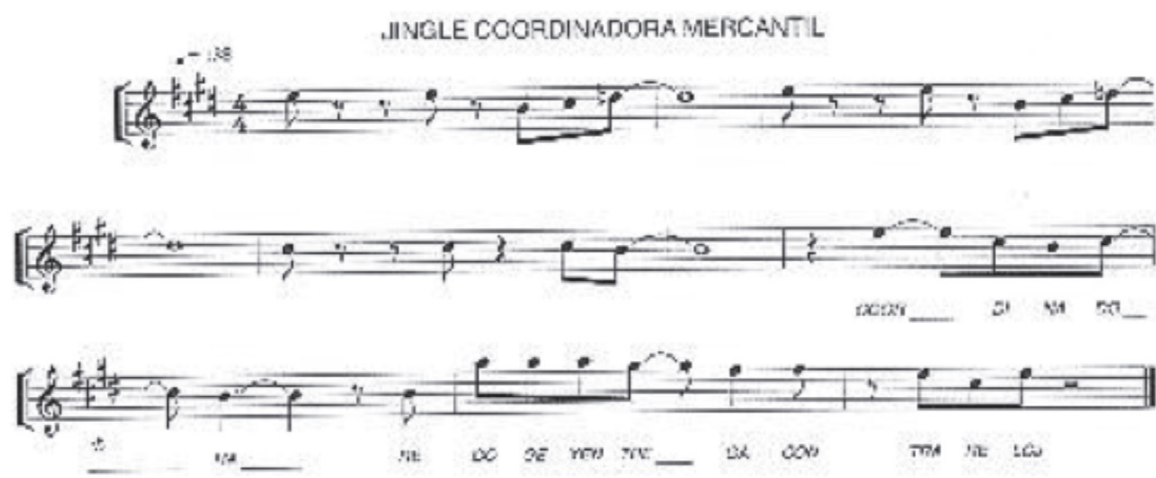

Marca: Jingle de la compañía transportadora Coordinadora

Registro SIC n. ${ }^{\circ} 415829$

Clase: 39

Territorio: Colombia

Fuente: http://sipi.sic.gov.co 


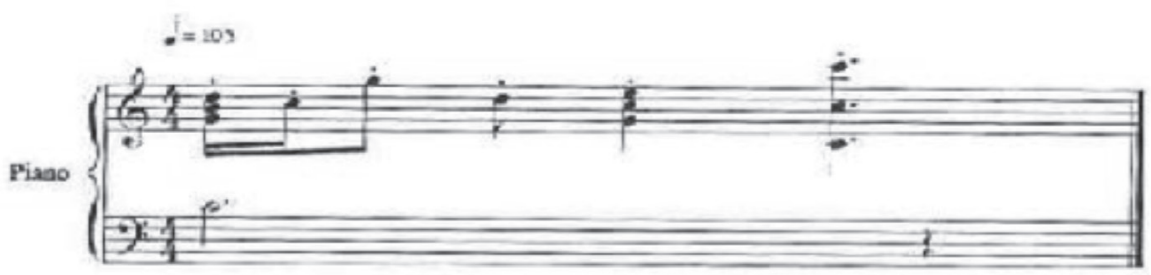

Marca: Jingle de Clorox

Registro sic n. ${ }^{\circ} 537573$

Clase: 3

Territorio: Colombia

Fuente: http://sipi.sic.gov.co

\subsection{Marcas gustativas}

Sabores ajenos a la naturaleza del producto que les son añadidos para otorgarle distintividad en el mercado; su objetivo es que los consumidores asocien el olor con el origen empresarial del producto. Se considera que son la más similares a las marcas olfativas, tanto por la dificultad de la representación gráfica como por la manera en la que cumplen el requisito de distintividad. Por este motivo, se explicarán un poco más a fondo que las clases anteriores.

\section{Distintividad}

Un sabor no tiene la capacidad inherente de hacer distintivo un producto en el mercado en razón de que no le permite al consumidor asociarlo con su origen empresarial. Sin embargo, existen dos formas de hacer que un sabor pueda cumplir con el requisito de distintividad. Estas son las siguientes: (1.) Que el sabor vaya combinado con un signo denominativo o figurativo, lo cual forma una sola marca compuesta que cumple de manera satisfactoria con el requisito de distintividad. En este caso, se exige que el sabor del producto sea totalmente novedoso y diferente al que habitualmente tienen los productos de la misma categoría en el mercado. (2.) Que el sabor del producto adquiera distintividad, sin tener la capacidad inherente para ello, [mediante] de la configuración del significado secundario, por medio de su uso prolongado e ininterrumpido en el mercado. Es evidente que en este supuesto también se exige que el sabor del producto sea totalmente novedoso y diferente al que habitualmente tienen los productos de la misma categoría en el mercado ${ }^{24}$. 
Sin embargo, la distintividad no deja de ser un problema o un requisito difícil de cumplir. En la mayoría de los casos se han rechazado solicitudes de registro de marcas gustativas por la falta de esta característica. En la resolución del asunto R 120/2001-2, la Euipo afirmó que:

Es improbable que el sabor sea percibido por el consumidor como una marca: es mucho más probable que presuma que su finalidad es disimular el sabor desagradable del producto. La Oficina de Patentes y Marcas de los Estados Unidos (USPTo) rechazó una solicitud similar, presentada por N. V. Organon para registrar el sabor a naranja como marca de productos farmacéuticos. Como señaló el Tribunal de Primera Instancia y de Apelación de Marcas, es difícil que un sabor actúe como marca cuando los consumidores solo lo experimentan después de haber comprado el producto ${ }^{25}$.

\section{Representación gráfica}

No hay consenso sobre la existencia de un medio idóneo para cumplir este requisito en las marcas gustativas. La manera de hacerlo sería mediante una descripción con palabras y/o el aporte de una muestra del sabor. Tan complicado es de lograr, que son casi nulos los casos de registros exitosos de una marca gustativa. De los pocos ejemplos que se pueden encontrar, hay uno que se dio en la Unión de Benelux (Bélgica, Holanda y Luxemburgo) sobre el registro de una marca que "consiste en el sabor a regaliz, aplicado a productos de la clase 16 (marca gustativa)"26.

Por otro lado, en el caso de los Estados Unidos se han intentado registrar ocho marcas gustativas, pero ninguna ha tenido éxito y siete han sido rechazadas de forma definitiva ${ }^{27}$.

\subsection{Marcas De COlor}

Este tipo de marca consiste en:

un determinado color, entendido este como un elemento que permite la individualización de un producto y que el cliente puede asociar de forma directa e inmediata con un producto y el empresario encargado de su producción o comercialización [...] (Ejemplo) la tonalidad rosa (para gaseosas) no representa visualmente para el consumidor una condición particular o intrínseca de productos derivados o con sabor a manzana, pues esta fruta suele tener dos colores predominantes (rojo o verde) ${ }^{28}$.

25 Organización Mundial de la Propiedad Intelectual (омpi). Olfato, oído, gusto. Los sentidos de las marcas no tradicionales [en línea]. Revista de la OMPI. Ginebra: OMPI, (febrero de 2009). ISSN: 1020-7082.

26 sct de la ompi. Op. cit.

27 Trademark Electronic Search System (TEss). [Página web] [Consultado en 2017] Disponible en http://tmsearch.uspto.gov/bin/gate.exe?f=tess\&state=4802:z15le4.8.1

28 Superintendencia de Industria y Comercio (sic). Resolución sic n. 33205 del 27 de mayo de 2014. 


\section{Distintividad}

La doctrina afirma que un color solo alcanza un carácter distintivo por medio de un significado secundario. En la decimoséptima sesión del SCT de la OMPI se dijo:

Los consumidores no suelen asociar los colores abstractos con una indicación de la fuente comercial, ya que su función esencial es por lo general estética, no distintiva. Un color o una combinación de colores solo puede tener carácter distintivo si se distingue claramente de los colores habitualmente asociados a la categoría del producto en cuestión [...] se pide a los solicitantes de la mayoría de los países europeos que acrediten que el signo de color cuya protección se solicita ha adquirido carácter distintivo gracias al uso relacionado con los productos o servicios señalados en la solicitud ${ }^{29}$.

Es por la necesidad de un significado secundario que las marcas de color cumplen con dificultad el requisito de distintividad.

\section{Representación gráfica}

Se hace depositando un ejemplar del color o haciendo referencia a un estándar reconocido.

EJEMPLOS DE MARCAS DE COLOR

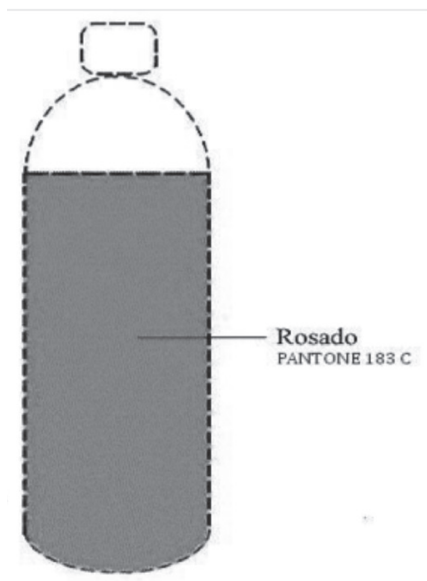

Marca: Color de la Manzana Postobón

Registro SIC n. ${ }^{\circ} 507282$

Clase: 32

Territorio: Colombia

Fuente: http://sipi.sic.gov.co/

29 sст de la омpi. Relación entre los principios existentes en materia de marcas y los nuevos tipos de marcas. En Comité Permanente sobre el Derecho de Marcas, Diseños Industriales e Indicaciones Geográficas. Decimoséptima sesión. Ginebra: OMPI, 2007. 
Marca: Color de Milacron LLC

Registro sic n. ${ }^{\circ} 485762$

Clase: 1

Territorio: Colombia

Fuente: http://sipi.sic.gov.co/
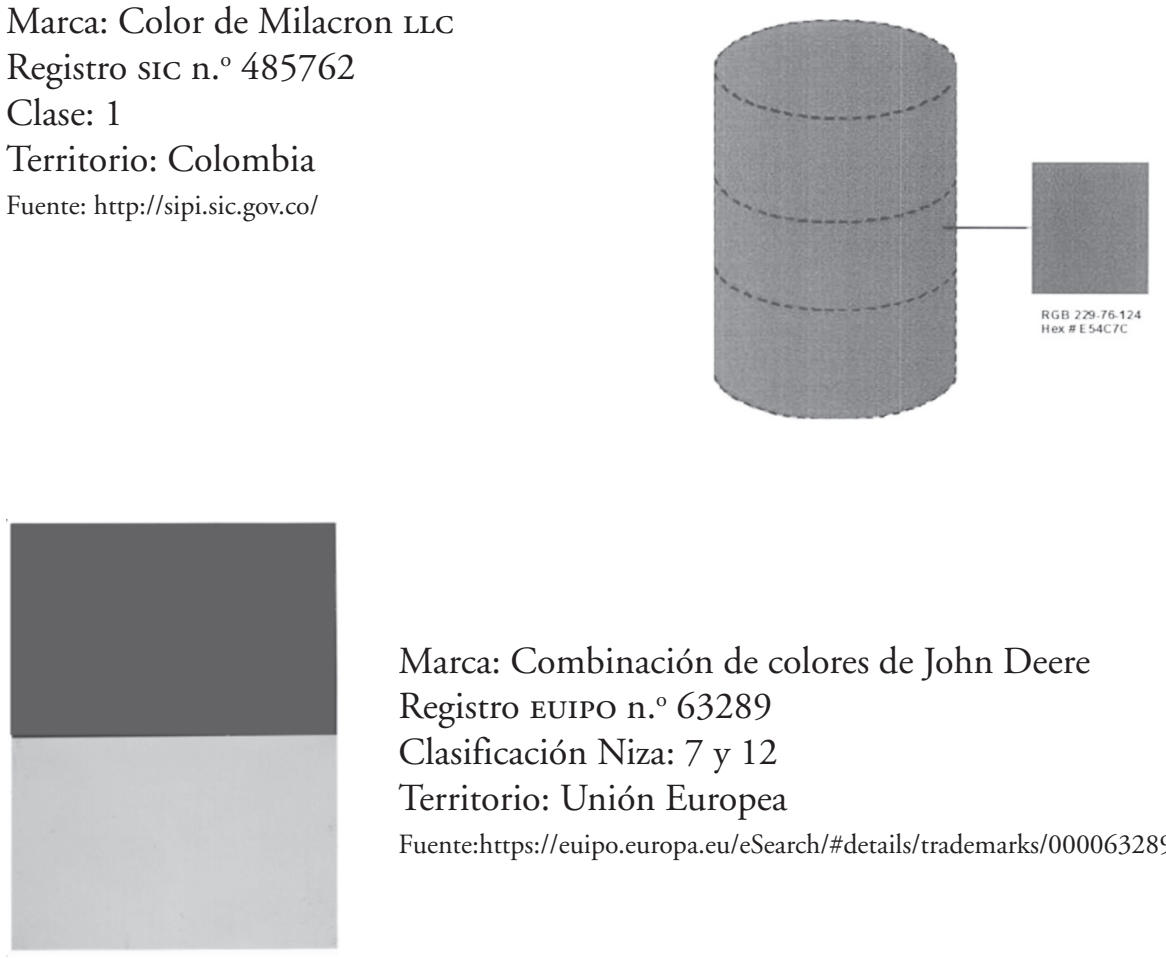

Marca: Combinación de colores de John Deere

Registro Euipo n. ${ }^{\circ} 63289$

Clasificación Niza: 7 y 12

Territorio: Unión Europea

Fuente:https://euipo.europa.eu/eSearch/\#details/trademarks/000063289

\section{LA MARCA OLFATIVA}

\section{I Noción}

Una marca olfativa es un signo percibido por el olfato. Este debe ser lo suficientemente distintivo y debe ser susceptible de representación gráfica para ser registra$\mathrm{do}^{30}$. Se observa entonces cómo la marca olfativa cuenta con las tres características de las marcas explicadas anteriormente.

Sobre la característica de perceptibilidad, se expondrán las opiniones de varios autores y los resultados de estudios realizados para dejar en evidencia la importancia de los olores como marcas en el mercado actual. Por su parte, en este punto se explicarán la distintividad y la representación gráfica.

\subsubsection{Perceptibilidad}

Los olores, los aromas y las fragancias son susceptibles de ser aprehendidos por el sentido corporal del olfato y asimilados por la inteligencia. En el portal web 
e-marketing.fr, Dominique Baulieu afirma que, de los cinco sentidos, el olfato es el que transmite el mayor valor sensorial, y que la memoria olfativa es la más potente. Se ha demostrado que el ser humano distingue primero los olores y después los sonidos, las texturas y los colores. Tanto es así que un niño de menos de dos semanas de nacido reconoce a su madre por el olor, y este lo consuela. Si un productor logra comunicar ese olor tranquilizador para su producto, el impacto en las ventas podría ser significativo ${ }^{31}$.

Un estudio realizado en 1999 por la Universidad de Rockefeller en Nueva York reveló lo siguiente:

[...] el ser humano recuerda el $35 \%$ de lo que huele, comparado con el $5 \%$ de lo que ve, el $2 \%$ de lo que oye y el $1 \%$ de lo que toca. Además, la memoria humana puede retener hasta 10.000 aromas distintos, mientras que solo reconoce 200 colores, según averiguaron Richard Axel y Linda Buck, coganadores del Premio Nobel de Medicina en $2004^{32}$.

Aterrizando el olfato al mercadeo, "numerosas experiencias han demostrado la influencia decisiva de los olores sobre el comportamiento de los compradores. Un olor agradable, por ejemplo, puede diluir la noción de tiempo en el consumidor y modificar su percepción visual y gustativa". ${ }^{33}$ Sobre la materia también se ha dicho que los recuerdos olfativos figuran entre los más evocadores; por este motivo, los fabricantes están cada vez más interesados en que los consumidores asocien sus productos con aromas agradables ${ }^{34}$.

Los siguientes apartes de un artículo de investigación que adelantó un comunicador de la Universidad Autónoma de Barcelona permiten hacerse una idea más completa sobre la importancia de los olores en el mercadeo y por qué en la actualidad los empresarios utilizan los olores para construir una identidad corporativa.

Cada día resulta más difícil construir marcas potentes, debido a la cantidad de competidores, la saturación de comunicaciones publicitarias, la dispersión de audiencias y la atomización de los medios tradicionales. Para diferenciar una marca es fundamental la identidad corporativa, que incluye los elementos que la harán visible y diferente para los consumidores. [...]

Pero la identidad de la marca debe tener en cuenta muchos otros elementos importantes: la tipografía, tono de voz, estilo de comunicación, color, símbolos, diseño

31 Baulieu, Dominique. Marketing olfactif ou all factice? [en línea], 2001. Disponible en http://www.e-marketing.fr/Marketing-Magazine/Article/Marketing-olfactif-ou-allfactice--6792-1.htm\#qClYP65IFbwT5LtK.97

32 Knowledge Wharton. What does your brand smell like? Philadelphia: University of Pennsylvania. 17 de octubre de 2007.

33 Castro García. Op. cit., pp. 297-325.

34 Organización Mundial de la Propiedad Intelectual. Op. cit. 
del packaging, música, textura, sabor y también el olor. Y todos ellos deben estar en línea. [...]

La capacidad de recordación de un aroma permanece en nuestra memoria más tiempo que un eslogan publicitario, y lo apreciable es que puede comunicar con intensidad emotiva los valores de marca.

Las empresas que han cuidado este aspecto en su producto se han encontrado, con el paso del tiempo, con una marca sólida, que permite ser reconocida por varios elementos, siendo el aroma uno de ellos ${ }^{35}$.

En resumen, empresarios y expertos en mercadeo han detectado desde hace tiempo el potencial que brinda el sentido del olfato, debido a su enorme poder evocador y sus estrechos vínculos con la parte más instintiva de nuestro comportamiento, que seducen por su prometedora capacidad para maximizar los resultados comerciales ${ }^{36}$.

\subsubsection{Distintividad}

Un olor, aroma o fragancia cumple un carácter distintivo si logra individualizar y diferenciar un producto de otros similares en el mercado. Esto implica que el olor no puede provenir de la naturaleza del producto, sino que se tiene que apartar de los olores habitualmente asociados con los productos de la misma categoría en la Clasificación de Niza. Es decir, el olor no puede tener relación con el producto al que se le pretende aplicar.

Los aromas que son el olor natural de un producto o que son habituales para los productos de la misma categoría suelen ser necesarios para los demás comerciantes, como en el caso del aroma de la vainilla. Este es un ingrediente presente en muchos productos alimenticios, por lo que sería imposible obtener la exclusividad sobre este en relación con el sector de la pastelería. Sucede lo mismo con los aromas que se suelen utilizar con fines de enmascaramiento en determinados productos, como ocurre con el aroma del pino en los desinfectantes y el aroma del limón en los productos de aseo. En estos tres ejemplos, el olor carecería de distintividad, sin embargo, la aplicación de un aroma a

35 Navalles, Pere. Los olores como marca comercial. Revista de Rinología. Barcelona: Universidad Autónoma de Barcelona, 2011, 11(2), pp. 23-28. IssN: 1578-4290.

36 Balaña, Sergio. El entorno digital, ¿segunda oportunidad para la marca olfativa? Estudio acerca de la capacidad del signo olfativo para funcionar como marca en el mercado. En Instituto de Derecho Industrial de la Universidad de Santiago de Compostela (España). Actas de derecho industrial y derecho de autor. Tomo XXVI. 2005-2006. Barcelonal Madrid: Universidad de Santiago de Compostela y Marcial Pons, Ediciones Jurídicas y Sociales, 2006, pp. 19-58. IsBN: 9788497683708. 
un producto que no lo suele tener tiene muchas posibilidades de adquirir un carácter distintivo ${ }^{37}$.

\subsubsection{Doctrina de la funcionalidad}

Para identificar si el olor puede contar con el requisito de distintividad, se ha implementado la doctrina de la funcionalidad, que consiste en lo siguiente:

Un signo susceptible de servir como marca no se puede registrar si constituye un elemento funcional de los productos, es decir, si es fundamental para el uso o el fin al que está destinado el producto o si afecta a su costo o a su calidad. La doctrina de la funcionalidad fue inicialmente creada para evitar el registro de las formas funcionales, pero también parece revestir pertinencia en el examen de otros signos no tradicionales, como los colores, los sonidos o los olores. Con esta doctrina se pretende fomentar la competencia legítima manteniendo el equilibrio adecuado entre los distintos ámbitos de la propiedad intelectual, como [...] la legislación sobre marcas. Se supone que vela por que se solicite la protección de los aspectos utilitarios del producto mediante una patente de utilidad de duración limitada, por ejemplo, y no mediante la posible protección ilimitada del registro de marca [...] Al evaluar si una característica del producto es funcional o no, también se debe determinar si los otros comerciantes necesitarán utilizar dicha característica (olor) en relación con productos similares ${ }^{38}$.

La doctrina de la funcionalidad supone un obstáculo de envergadura en las aspiraciones marcarias de un gran número de signos olfativos; de hecho, gran parte de la doctrina que se ha posicionado en contra de este tipo de marcas lo ha hecho precisamente enarbolando el estandarte de la funcionalidad [...] [Esta doctrina] responde a la preocupación de impedir restricciones indebidas en la competencia debido a la monopolización de una forma que se considere necesaria para la comercialización con éxito del producto de que se trate ${ }^{39}$.

Esta doctrina responde a la esencia de lo que es un signo distintivo, ya que sin ella se podría interpretar que los elementos naturales y que cumplen alguna función en un producto se pueden utilizar como marcas. De esta manera, se desvirtuaría lo que es una marca comercial.

37 SCT de la OMpi. Relación entre los principios existentes en materia de marcas y los nuevos tipos de marcas. Op. cit.

38 Idem.

39 Balaña. Op. cit., pp. 19-58. 


\subsubsection{Representación gráfica}

La representación gráfica reviste el mayor impedimento para lograr el registro exitoso de un signo olfativo. Las propuestas que la doctrina ha hecho para lograr el cumplimiento de este requisito se reúnen en las siguientes tres: una descripción de palabras del olor, la fórmula química de un análisis cromatográfico en la fase gaseosa del olor, el depósito de una muestra del olor o una combinación de las tres.

El sct de la OMPI ha manifestado que el registro de las marcas no tradicionales constituye un ámbito que suscita el interés en los Estados miembros de la OMPI. Por este motivo, y con el fin de que proliferen los casos de registros exitosos de marcas olfativas, en su decimonovena sesión, ha sugerido lo siguiente:

[...] su representación puede consistir en una descripción escrita del olor. Esa representación se realizará de manera que se transmita a una persona normal y corriente la información necesaria para identificar adecuadamente la marca. Por lo general, deberá incluirse una indicación del tipo de marca de que se trate $e^{40}$.

Sin embargo, esta solución ha sido desestimada en múltiples ocasiones por la doctrina y por las oficinas de registro y autoridades jurisdiccionales. La EuIPo dijo que:

La descripción de un olor, aun cuando sea gráfica, no resulta admisible como representación del signo, del olor, pues no resulta suficientemente precisa y objetiva. Una descripción con palabras es una mera aproximación al olor que se trata de apropiar, que no puede llegar a ser íntegra, clara, precisa y objetiva ${ }^{41}$.

Por su parte, el Tribunal de Justicia de la Unión Europea desestimó las tres posibilidades de representación gráfica cuando, en sentencia del 12 de diciembre de 2002, afirmó lo siguiente:

En el caso de un signo olfativo, el requisito de la representación gráfica no se cumple mediante una fórmula química, una descripción con palabras escritas, el depósito de una muestra del olor en cuestión ni una combinación de dichos elementos [...] Por lo que se refiere a la fórmula química, [...] pocas personas serían capaces de reconocer, en una fórmula de ese tipo, el olor en cuestión. Tal fórmula no resulta suficientemente inteligible. Por otro lado, una fórmula química no representa el olor de una sustancia, sino la sustancia en cuanto tal, y, por lo demás, tampoco resulta suficientemente clara y precisa. Por lo tanto, la fórmula química no es una representación [...] En lo que atañe al depósito de una muestra de un olor, es preciso señalar que no constituye una

40 sст de la омpi. La representación y la descripción de marcas no tradicionales. Posibles ámbitos de convergencia. En Comité Permanente sobre el Derecho de Marcas, Diseños Industriales e Indicaciones Geográficas. Decimonovena sesión. Ginebra: OMPI, 2008.

41 Oficina de Armonización del Mercado Interior (oАmi). El olor a limón (marca olfativa). R 0445/2003-4 del 12 de diciembre de 2015. 
representación gráfica a efectos del artículo 2 de la Directiva. Por otro lado, una muestra de un olor no es lo suficientemente estable ni duradera ${ }^{42}$.

El doctrinante Rodolfo Lizarazu Montoya concuerda con la opinión del Tribunal respecto al depósito de una muestra del olor, ya que esta no "tendrá estabilidad ni duración definida, lo que haría incierta la fragancia, y porque la muestra en sí no es una representación gráfica de la marca" ${ }^{3}$.

\section{ESTADO DEL ARTE}

Se explicará a continuación, con fines ilustrativos, la situación de las marcas olfativas en otras regiones, para tener una idea de cómo ha sido el desarrollo del tema en el mundo en comparación con Colombia.

\section{I Estados Unidos}

En este país, para el registro de las marcas no visuales, como la olfativa, no se exige la representación gráfica, sino simplemente un escrito con una descripción clara y detallada del signo ${ }^{44}$. Quien quiera el registro, solo tiene que probar la no funcionalidad (ver punto 5.1.2.1 Doctrina de la funcionalidad) y la distintividad.

Tal vez por este motivo fue en esta nación donde se dio el primer registro de una marca de olor, en 1990. La compañía Clark solicitó la protección de un olor que describió como "una fragancia de alto impacto, fresca, floral, muy intensa, que recuerda la de las flores de plumería" para emplearla en hilos de coser y de bordar. La marca se concedió y luego, en 1997, se canceló por falta de uso. El caso se conoce como el asunto In re Clarke (17 U.S.P.Q.2d 1238 ттАв 1990).

Tras este precedente, se han presentado varios registros más, como los siguientes:

- (US 2560618): Midwest Biologicals solicitó la protección de un “aroma de bubble gum" para aceites industriales - "Oil based metal cutting fluid and oil based metal removal fluid for industrial metal working". Fue concedido.

- (US 2463044): Mantel, Mike registró el aroma de cereza para lubricantes sintéticos para vehículos - "Synthetic lubricants for high performance racing and recreational vehicles".

- (US 2568512): Mantel, Mike logró el registro del aroma de uva "the grape scent of godos" para lubricantes y aceites para motor - "Lubricants and motor fuels for land vehicles, aircraft, and watercraft".

42 Tribunal de Justicia de la Unión Europea (TJUE). Ralf Sieckmann v. Deutsches Patent-un Markenamt. C-273/00 del 12 de diciembre de 2002.

43 Lizarazu Montoya. Op. cit., p. 51.

44 Oficina de Patentes de los Estados Unidos. Trademark Manual of Examining Procedure [en línea]. 3. ${ }^{a}$ ed. Wahington: Autor, 2002. IsBn: 978-1588530530. Disponible en https://tmep.uspto.gov 
- (US 3140700): The Smead Manufacturing Company pidió el registro del aroma de menta "peppermint scent or fragrance" para productos de oficina y carpetas - "Office supplies, namely, file folders, hanging folders, paper expanding files". ${ }^{45}$

\subsection{EURopa}

En la Unión Europea es posible registrar una marca tanto a nivel nacional -acudiendo a la oficina de cada país- como a nivel comunitario, optando por la marca de la Unión Europea (antes llamada Marca Comunitaria), que confiere protección al derecho marcario del solicitante en todos los Estados miembros. Para obtener un registro comunitario válido, el solicitante debe cumplir todos los requisitos del Reglamento sobre la marca comunitaria ${ }^{46}$. La regulación y las autoridades competentes domésticas de algunos países de la Unión Europea son más flexibles que las comunitarias en cuanto al registro de marcas olfativas. Como consecuencia, varios signos de olor que se han registrado en naciones europeas no han alcanzado el mismo éxito con la Oficina de Propiedad Intelectual de la Unión Europea (Euipo por sus siglas en inglés).

Solo un signo lo ha logrado, y es "el olor del césped recién cortado aplicado a pelotas de tenis" (clase 28 en la Clasificación de Niza) por parte de la compañía holandesa Vennootschap Onder Firma. La solicitud se presentó en 1996, el registro se otorgó el 11 de octubre de 2000 y expiró el 11 de diciembre de 2006. La EUIPO sentenció:

El olor a césped recién cortado es un olor distintivo que todos reconocen inmediatamente por experiencia. Para muchos, el olor o fragancia del césped recién cortado evoca la primavera o el verano, prados o campos de juego bien cuidados u otras experiencias agradables similares. La Sala considera que la descripción proporcionada para la marca olfativa que se pretende registrar es apropiada y cumple con el requisito de representación gráfica del artículo 4 del Reglamento sobre la marca comunitaria".

Aparte de este, se han presentado seis solicitudes de marcas de olor. Cinco de ellas fueron rechazadas y una fue retirada por el solicitante ${ }^{47}$.

En el Reino Unido se han registrado varias marcas olfativas, entre las que se encuentran las siguientes:

- (UK 2001416): El 9 de abril de 1996, Goodyear Dunlop registró como marca una fragancia floral/olor a rosas aplicada a llantas (clase 12 en Clasifica-

45 Trademark Electronic Search System. Op. cit.

46 Escoffier, Luca y Jin, Arnold. To scent, or not to scent, that is the question: A comparative analysis of olfactory trademarks in the EU and US as good brand opportunities for SME. [Sin fecha].

47 European Union Intellectual Property Office (Euipo). [Página web] https://euipo. europa.eu/eSearch/\#advanced/trademarks/1/50/n1=MarkFeature\&v1 =Olfactory\&o1=AND \&sf=ApplicationNumber\&so=asc [Consultado en junio de 2017] 
ción de Niza), "the trade mark is a floral fragrance/ smell reminiscent of roses as applied to tyres".

- (UK 2000234): El 3 de mayo de 1996, Unicorn Products Limited consiguió el registro como marca del olor fuerte a cerveza amarga aplicada a dardos, "the mark comprises the strong smell of bitter beer applied to flights for darts" 48 .

- Chanel intentó registrar su perfume $\mathrm{n}^{\circ}{ }^{\circ}$, sin embargo, este fue negado debido a que el olor es la esencia misma del producto, y en una marca olfativa el olor no puede derivar de la propia naturaleza del producto $^{49}$.

Si bien se presentan casos como el del Reino Unido, en países como España no se permite el registro de marcas olfativas. El argumento en este país es que un olor no puede ser representado gráficamente, por ende, no puede cumplir el requisito que trae la regulación doméstica en el artículo 4.1 de la Ley $17 / 2001^{50}$.

\subsubsection{Cambios en la regulación europea}

El Reglamento 2015/2424 del Parlamento Europeo y del Consejo que corresponde al procedimiento de registro de la marca de la Unión Europea, cuyo articulado completo entra en vigor desde el primero de octubre de 2017, modifica trascendentalmente el esquema de registro de las marcas olfativas en la Unión Europea. Este elimina el requisito de representación gráfica para las marcas que puedan ser individualizadas en un tipo de soporte diferente a una representación visual, entre las que está la marca de olor ${ }^{51}$. En el considerando noveno del Reglamento se explica:

A fin de permitir una mayor flexibilidad y garantizar al mismo tiempo una mayor seguridad jurídica en cuanto a los medios de representación de marcas, el requisito de representación gráfica debe suprimirse de la definición de marca de la Unión. Se debe permitir que un signo se represente de cualquier forma que se considere adecuada usando la tecnología generalmente disponible, y no necesariamente por medios gráficos, siempre que la representación sea clara, precisa, autosuficiente, fácilmente accesible, inteligible, duradera y objetiva.

48 Intellectual Property Office. [Página web] [Consultado en 2017] Disponible en https://www.gov.uk/search-for-trademark

49 Organización Mundial de la Propiedad Intelectual. Op. cit.

50 Ávila Vallecillo, José. Marcas olfativas: ¿un derecho evolutivo o restrictivo? Perspectiva del derecho comparado (Honduras-Colombia). Revista Ciencia y Tecnología. Honduras: UNAH, 2015, (16), pp. 133-149. ISSN: 1995-9613.

51 Serrano Castillo, Juan Manuel. (26 de abril de 2017). Eliminado requisito de representación gráfica en el Reglamento Europeo para el registro de marca [en línea]. Disponible en http://www.sic.gov.co/ruta-pi/eliminado-requisito-de-representacion-grafica-enel-reglamento-europeo-para-el-registro-de-marca [Consultado en 2017] 
De esta manera se elimina el requisito que la doctrina ha calificado como uno de los mayores impedimentos para obtener el registro de una marca olfativa. "Muchos profesionales del sector entienden que la desaparición de este requisito implica el desbloqueo para el registro de las marcas olfativas que hasta ahora respondía fielmente a los requisitos Sieckman" ${ }^{\text {". }}$. Hasta ahora la Unión Europea solo cuenta con un registro exitoso de marca olfativa, y se espera que con la supresión del requisito de representación gráfica esa cifra pueda aumentar.

\section{MARCAS OLFATIVAS EN COLOMBIA}

\section{I Regulación}

La legislación interna aplicable es principalmente la Decisión 486 del 14 de septiembre de 2000 del Acuerdo de Cartagena. Esta derogó la mayoría de las disposiciones sobre marcas del Código de Comercio, y las que aún están vigentes son sobre aspectos del contrato de licencia (art. 594), disposiciones sobre extranjeros que soliciten el registro de marcas y medidas cautelares (art. 597), nombres y enseñas comerciales (arts. 603-611) y disposiciones procesales (arts. 612-618).

La mencionada decisión dispone expresamente la posibilidad de registrar marcas olfativas en su artículo 134, literal c.

Artículo 134: A efectos de este régimen, constituirá marca cualquier signo que sea apto para distinguir productos o servicios en el mercado. Podrán registrarse como marcas los signos susceptibles de representación gráfica. La naturaleza del producto o servicio al cual se ha de aplicar una marca en ningún caso será obstáculo para su registro.

Podrán constituir marcas, entre otros, los siguientes signos:

\section{$[\ldots]$}

c) los sonidos y los olores.

\subsection{Práctica}

La claridad de la regulación resulta en que no haya dudas sobre la permisión legal de registrar marcas olfativas en el país. Sin embargo, en Colombia no hay hasta la fecha ni un solo registro exitoso. La Superintendencia de Industria y Comercio ha afirmado en dos conceptos que sí es posible registrar una marca olfativa en Colombia y expuso los requisitos para que esta se diera, pero todavía ningún solicitante ha 
podido satisfacer esas exigencias. Se han presentado tres solicitudes, de las cuales dos fueron negadas y la otra se encuentra apenas bajo el examen formal.

El 17 de mayo de 2005, Laboratorios Cero S. A. solicitó el registro un olor que describió por medio del siguiente gráfico para los productos de la clase 8 de la Clasificación de Niza, a saber:

cremas antipañalíticas no medicadas, geles, champús, vaselinas, aceites corporales, protectores labiales, removedores, talcos, así como preparaciones para blanquear y otras sustancias para la colada; preparaciones para limpiar, pulir, desengrasar y raspar; (preparaciones abrasivas) jabones; perfumería, aceites esenciales, cosméticos, lociones para el cabello; dentífricos.

\section{CROMATOGRAMA}

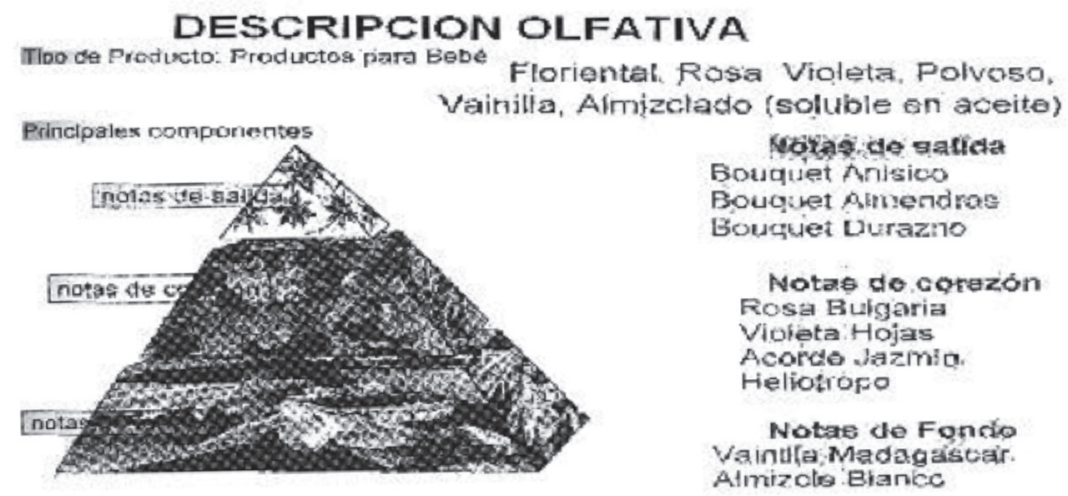

La Superintendencia de Industria y Comercio negó la solicitud mediante la Resolución n. ${ }^{\circ} 011956$ bajo el argumento de que la descripción aportada no cumplía el requisito de representación gráfica y que, aunque lo cumpliera, este carece de distintividad.

En la Resolución, el ente administrativo hace una explicación sobre lo que es la representación gráfica y su cumplimiento en los signos olfativos. Sigue los lineamientos del caso Sieckman (ver punto 5.1.3 Representación gráfica) y deses- 
tima los tres mecanismos conocidos para cumplir el requisito, pero deja abierta la posibilidad de que en un futuro exista alguna forma de representar gráficamente de manera válida un olor.

La representación gráfica debe ser comprensible, y para llegar a serlo necesitará ser completa, clara y precisa, cualidades que les permiten tanto a los consumidores como a los competidores conocer sin duda alguna qué es lo que se monopoliza.

La marca olfativa no puede ser reproducida de manera gráfica, ya que la fórmula química no representa el olor de la sustancia, sino la propia sustancia, es decir, el producto, generándose así una incongruencia, pues de solicitarse la fórmula, lo que realmente se pretende proteger es un producto específico compuesto por químicos y determinadas cantidades de componentes, y no un olor determinado. Por su complejidad, se deduce que pocos serían capaces de descifrar un olor partiendo de la fórmula que representa el producto del cual emana. [...]

Un signo que en sí mismo no permite su percepción visual puede constituirse como marca siempre que pueda ser objeto de representación gráfica, en particular por medio de figuras, líneas o caracteres, que sea clara, precisa, completa en sí misma, fácilmente accesible, inteligible, duradera y objetiva.

El requisito de representación gráfica aplicado a los signos olfativos no se cumple mediante una fórmula química, una descripción de palabras, el depósito de una muestra del olor en cuestión ni una combinación de las anteriores posibilidades.

En conclusión, el depósito en el registro de una muestra [del] producto químico que produce el olor no se considera la representación gráfica del signo distintivo; aun de admitirse una muestra del olor que se pretende registrar, se encuentran inconvenientes relativos a su claridad y precisión por factores tales como el paso del tiempo y la volatilidad de sus componentes.

No puede negarse, sin embargo, que en un momento dado un signo olfativo pueda ser susceptible de representación gráfica, ya que la tecnología ha venido desarrollando diversos sistemas para dibujar olores, pero en la actualidad estos avances presentan dificultades en la expresión visual del signo $0^{53}$.

Sobre el caso en concreto, la sic afirmó en la Resolución que "la descripción adjuntada por parte del solicitante es realmente la fórmula como se crea o fabrica el producto, y debe tenerse en cuenta que el aroma que este genera es parte del producto mismo". Más adelante dice que "el signo solicitado, por no ser susceptible 
de ser representado gráficamente, no es capaz de constituirse como marca, por lo que no es procedente su registro".

Va más allá de la representación gráfica y hace referencia a la distintividad al concluir lo siguiente:

Aunque en un momento dado sea susceptible de ser representado gráficamente el signo, este por sí mismo carece de la distintividad intrínseca que se espera de las marcas, pues el olor que se pueda percibir no va más allá del común de los olores que puede llegar a producir cualquier producto cosmético o higiénico comprendido en la clase 3 internacional (clase 8 de la Clasificación de Niza), por lo que no crea un concepto nuevo en el mercado que permita a los consumidores identificar su origen empresarial a partir de su fragancia, más aún si se tiene en cuenta que este tipo de productos usualmente están dotados de aromas.

Se considera errónea la afirmación de la Sic al decir que de las marcas se espera una distintividad intrínseca, ya que, como se ha visto (ver punto 4. Marcas no tradicionales), hay tipos de marcas que carecen de distintividad intrínseca y la adquieren por medio del significado secundario. A pesar de esto, se considera que el signo solicitado sí carece de distintividad, puesto que no va más allá de la funcionalidad del producto, ya que el olor es parte del producto mismo y cualquier producto de esa clase tiene olores como los que se pretenden registrar. De esta manera, el signo no se ajusta a la doctrina de la funcionalidad (ver punto 5.1.2.1 Doctrina de la funcionalidad).

El 7 de abril de 2010, tres años después de negada la primera solicitud de un signo olfativo en Colombia, la empresa de servicios públicos Empresas Públicas de Medellín (ЕPM) radicó una solicitud de signos distintivos sobre un olor. Solicitó la marca para los servicios de la clase 9 de la Clasificación de Niza, que son "publicidad, gestión de negocios comerciales, administración comercial, trabajos de oficina”. Describió el signo así:

Olor compuesto por (a) un fondo predominante de carácter cítrico, integrado con (b) un toque destacado de aroma a jazmín y, (c) de manera complementaria, notas ligeras consistentes en mezclas de jazmín con limón, eucalipto con menta y limoncillo. Evoca un ambiente campestre relacionado con lugares cercanos a naturaleza pura y viva, generando sensaciones de vitalidad, confort, tranquilidad y frescura.

También aportó la siguiente fórmula: 


\begin{tabular}{|c|c|}
\hline COMPUESTO & $\%$ \\
\hline Acido ciclopenten aceitco. 3 oxo 2 pentil metil ester & 21,113 \\
\hline Limoneno & 17,013 \\
\hline Dipropilenglicol monoetileter & 14,398 \\
\hline 2,6 octadien 1 ol 3,7 dimetil & 12,668 \\
\hline Linalil isobutirato & 7,833 \\
\hline Octanal & 6,826 \\
\hline Acido ciclopentaneacetico. 3-0xo 2-pentil metal ester & 2,864 \\
\hline (7a-isopropenil-4,5-dietiloctahidroinden-4-il) metanol & 2,313 \\
\hline 1,2 dihidrolinalol & 2,203 \\
\hline 3 buten 2 on $4-(2,6,6$ trimetil 1 ciclohexen 1 ii) & 2,000 \\
\hline 2 Butanol 3,3' oxybis & 1,680 \\
\hline Dietiltalato & 1,560 \\
\hline Tonalio & 1,500 \\
\hline Acido benzene acetico. 2-fenil etil ester & 0,861 \\
\hline 7 octen 2 ol 2,6 dimetil & 0,848 \\
\hline 2,6 octadien 1 ol 3,7 dimetil acetato & 0,646 \\
\hline 2,6 octadienal 3,7 dimetil & 0,624 \\
\hline 3 cidohexen 1 carboxaldehido 3,4 dimetil & 0,606 \\
\hline $\begin{array}{l}\text { 2-(4a.8-Dimetil-6-oxo-1.2.3.4,4a.5.8a-octahidro naftalen } 2 \text { il) } \\
\text { propionaldèhido }\end{array}$ & 0,554 \\
\hline Mentol & 0,516 \\
\hline $1 \mathrm{H}$ indene $2,3,3$ a 4,7 a hexahidro $2,2,4,4,7,7$ hexametil & 0,485 \\
\hline a-isometil ionona & 0,464 \\
\hline Hexanol & 0,368 \\
\hline Trazas de impurezas irrelevantes en el análisis. & 0,057 \\
\hline TOTAL & 100,00 \\
\hline
\end{tabular}

Mediante la Resolución n. ${ }^{\circ} 1765$ del 26 de enero de 2011, la sic realizó un análisis muy similar al de la resolución del caso mencionado anteriormente. No concedió el registro de la marca bajo el argumento de que "el signo solicitado, por no ser susceptible de ser representado gráficamente, no es capaz de constituirse como marca". Afirmó que "la fórmula que adjunta el solicitante en el expediente para los servicios solicitados refiere el compuesto como se crea o fabrica el producto, y debe tenerse en cuenta que el aroma que este genera es parte del producto mismo" ${ }^{54}$.

Luego de negadas las dos solicitudes, la sic emitió dos conceptos, el número 30326 del 13 de mayo de 2011 y el número 75464 del 8 de agosto de 2011. En el primero afirmó que sí se puede registrar una marca olfativa en Colombia. Sobre el cumplimiento del requisito de distintividad, dijo: 
De acuerdo con la normatividad aplicable en Colombia, la probabilidad de registro de un signo olfativo sería más efectiva si el solicitante aporta[ra] pruebas sobre la distintividad que ha adquirido en el mercado, esto es, que un porcentaje representativo de consumidores reconocen el aroma como una marca de los productos respectivos, en aplicación del último inciso del artículo 135 de la Decisión 489 Andina.

En el segundo concepto se refirió de manera amplia a la representación gráfica. Reiteró que debe ser clara, precisa, duradera, completa y objetiva, y dijo que en el caso de las marcas olfativas puede cumplirse por medio de una "descripción, de la cual debe [formar] parte la fórmula química, (que sea) íntegra, clara, precisa y comprensible para la generalidad de los fabricantes y consumidores del olor que quiere registrarse como marca, podría llegar a ser una forma de representación gráfica admisible" 55 .

Actualmente hay un signo olfativo solicitado que se encuentra en la etapa del examen de forma, lo solicitó la Universidad Industrial de Santander el 22 de febrero de 2017 para los productos de la clase 11 de la Clasificación de Niza, que son gel antibacterial, splash repelente, aceite para masajes, jabón líquido y sólido. La representación gráfica del signo la hicieron mediante la siguiente "descripción cromatográfica de la marca”.

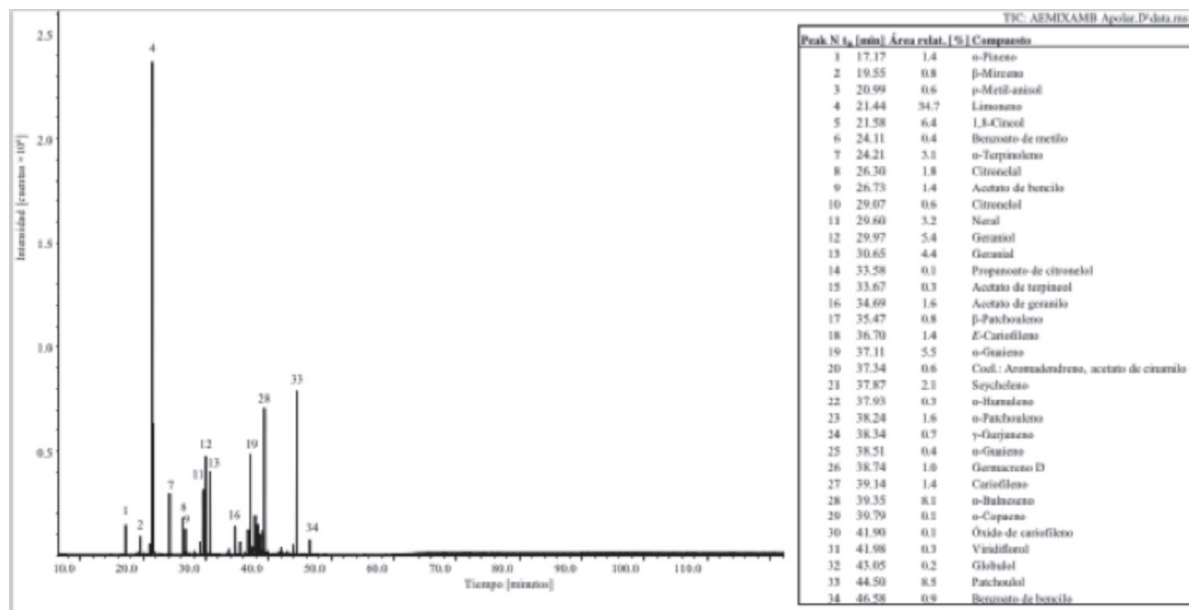

Este es el "perfil cromatográfico de la mezcla de AE empleada en formulación de ambientador repelente Chicamocha Magic".

Con base en las resoluciones y los conceptos mencionados en este acápite, se puede afirmar que esta nueva solicitud va a ser negada por no cumplir tanto el requisito de representación gráfica como el de distintividad. La sic ha sido clara en 
afirmar que la representación gráfica no se cumple mediante una fórmula química, también en decir que el olor no puede ser parte del producto mismo, y se considera que un olor para un repelente es parte de este y cumple una función en él.

\section{CONCLUSIONES}

En la actualidad no se puede registrar una marca olfativa en Colombia. Si bien la regulación lo permite y la Superintendencia de Industria y Comercio ha dicho a lo largo de sus pronunciamientos que sí es posible el registro de un signo de olor, esto por ahora es una abstracción que no se puede llevar a la práctica debido a que no se puede cumplir la representación gráfica de manera correcta.

Con sus resoluciones, la autoridad colombiana contradice los dos conceptos que ha emitido afirmando que sí se pueden registrar los olores como marcas. En estas decisiones se ciñe a la doctrina del caso Sieckman y no considera válidos los tres mecanismos que permiten la tecnología hoy para representar gráficamente un olor (ver punto 5.1.3 Representación gráfica), simplemente plantea la eventualidad de que en un futuro se puedan registrar al decir que "no puede negarse, sin embargo, que en un momento dado un signo olfativo pueda ser susceptible de representación gráfica, ya que la tecnología ha venido desarrollando diversos sistemas para dibujar olores".

En ese sentido, solo se podrá registrar una marca olfativa en el país si se presenta una de dos situaciones: si progresa la tecnología al punto que se pueda representar gráficamente un olor de una manera diferente a las tres conocidas y desestimadas por la sic o si hay un cambio en la regulación.

En cuanto al progreso tecnológico, Luca Escoffier y Arnold Jin previeron como necesarios los siguientes supuestos para la representación gráfica de un olor:

1. La creación y amplia difusión de computadores con dispositivos de emisión de olores o fragancias incorporados.

2. La adopción de una clasificación internacional con categorías bien definidas de olores o fragancias con muestras duraderas y estables que sean accesibles en línea.

3. La adopción, por parte de la autoridad competente, de una base de datos en la cual esas muestras puedan presentarse junto con la solicitud, almacenarse y ponerse a disposición del público para futuras búsquedas ${ }^{56}$.

Esta posición es adecuada debido a que el escenario para que el desarrollo de la tecnología permita la representación de un olor, y su posterior registro, implica que se pueda obtener una muestra duradera y estable del olor que pueda ser fácil y objetivamente perceptible por el público mediante la consulta de la base de datos de la autoridad competente.

$\mathrm{Si}$ en el futuro se presentaran los avances tecnológicos mencionados, la Superintendencia de Industria y Comercio contaría con la capacidad de adaptarse a 
los cambios y Colombia tendría la posibilidad real de registrar marcas olfativas. Así lo ha afirmado uno de sus funcionarios, el coordinador del Grupo de Oposiciones y Cancelaciones de la Delegatura para la Propiedad Intelectual, al decir que, "al igual que la euipo, la Superintendencia de Industria y Comercio cuenta con los medios tecnológicos para la presentación de marcas no tradicionales en nuevos soportes, para ser recibidas y consultadas por el público" ${ }^{15}$.

Por otro lado, el panorama mundial es alentador para un cambio en la regulación. Próximamente entrará en vigor la supresión del requisito de representación gráfica para marcas no visuales en la Unión Europea. Con este antecedente aumenta la probabilidad de que la Comunidad Andina de Naciones le siga los pasos al Parlamento Europeo y modifique su normativa, ya que los sistemas internacionales de marcas buscan siempre la estandarización en sus requisitos para el registro de las marcas.

Ahora bien, aunque se lleguen a dar las condiciones para que se pueda representar gráficamente un olor en Colombia, los solicitantes igual deberán lograr la difícil tarea de demostrar que el signo olfativo cumple el requisito de distintividad. Se califica como difícil, puesto que el olor no puede ser un elemento natural del producto ni cumplir alguna función en él diferente a la de individualizar, identificar y diferenciar a este de los demás similares, y porque, en la práctica, deberán probar una distintividad adquirida, en la que parte de los consumidores reconozcan el olor como marca del respectivo producto.

\section{BIBLIOGRAFÍA}

Ávila Vallecillo, José. Marcas olfativas: ¿̨un derecho evolutivo o restrictivo? Perspectiva del derecho comparado (Honduras-Colombia). Revista Ciencia y Tecnología. Honduras: UNAH, 2015, (16), pp. 133-149. Issn: 1995-9613.

Balaña, Sergio. El entorno digital, ¿̇segunda oportunidad para la marca olfativa? Estudio acerca de la capacidad del signo olfativo para funcionar como marca en el mercado. En Instituto de Derecho Industrial de la Universidad de Santiago de Compostela (España). Actas de derecho industrial y derecho de autor. Tomo XXVI. 2005-2006. Barcelona/Madrid: Universidad de Santiago de Compostela y Marcial Pons, Ediciones Jurídicas y Sociales, 2006, pp. 19-58. ISBN: 9788497683708.

Baulieu, Dominique. Marketing olfactifou all factice? [en línea], 2001. Disponible en http://www.e-marketing.fr/Marketing-Magazine/Article/Marketing-olfactifou-all-factice--6792-1.htm\#qClYP65IFbwT5LtK.97

Castro García, Juan David. Las marcas no tradicionales. Revista La Propiedad Inmaterial. Bogotá: Universidad Externado de Colombia, 2012, (16), pp. 297-325. ISSN: 1657-1959. 
Comunidad Andina de Naciones (CAN). Decisión 486: Régimen Común sobre Propiedad Industrial. 14 de septiembre de 2000.

Escoffier, Luca y Jin, Arnold. To scent, or not to scent, that is the question: A comparative analysis of olfactory trademarks in the EU and US as good brand opportunities for SME. [Sin fecha].

European Union Intellectual Property Office (euipo). s. f. Disponible en https:// euipo.europa.eu/eSearch/\#advanced/trademarks/1/50/n1=MarkFeature\&v1 = Olfactory\&o1=AND\&sf=ApplicationNumber\&so=asc (último acceso: 2017).

GALLEGo, LorenA. 2017: ¿tenemos finalmente registro de marca olfativa? [en línea], 2016. Disponible en http://www.legaltoday.com/blogs/nuevas-tecnologias/ blog-ecija-2-0/2017-tenemos-finalmente-registro-de-marca-olfativa.

Intellectual Property Office. s.f. https://www.gov.uk/search-for-trademark

Knowledge Wharton. What does your brand smell like? Philadelphia: University of Pennsylvania. 17 de octubre de 2007.

Liévano Mejía, José Daniel. Aproximación a las marcas no tradicionales. Versión actualizada y complementada. Bogotá: Pontificia Universidad Javeriana. [Sin fecha].

Lizarazu Montoya, Rodolfo. Manual de propiedad industrial. Bogotá: Legis Editores, 2014. IsBn: 978-958-767-217-6.

Navalles, Pere. Los olores como marca comercial. Revista de Rinología. Barcelona: Universidad Autónoma de Barcelona, 2011, 11(2), pp. 23-28. IssN: 1578-4290.

Oficina de Armonización del Mercado Interior (OAMI). El olor a limón (marca olfativa). R 0445/2003-4 del 12 de diciembre de 2015.

Oficina de Patentes de los Estados Unidos. Trademark Manual of Examining Procedure [en línea]. 3. ${ }^{a}$ ed. Washington: Autor, 2002. IsBN: 978-1588530530. Disponible en https://tmep.uspto.gov

Organización Mundial de la Propiedad Intelectual (ompI). Olfato, oído, gusto. Los sentidos de las marcas no tradicionales [en línea]. Revista de la OMPI. Ginebra: OMPI, (febrero de 2009). ISSN: 1020-7082.

Pachón, Manuel y Sánchez Ávila, Zoraida. El Régimen Andino de la Propiedad Industrial. Bogotá: Ediciones Jurídicas Gustavo Ibáñez, 1995.

Ruiz-Jarabo Colomer, Damaso. Conclusiones sobre el Asunto C-273/00. 6 de noviembre de 2001.

Serrano Castillo, Juan Manuel. Eliminado requisito de representación gráfica en el Reglamento Europeo para el registro de marca [en línea], 2017. Disponible en http://www.sic.gov.co/ruta-pi/eliminado-requisito-de-representacion-graficaen-el-reglamento-europeo-para-el-registro-de-marca [Consultado en 2017]

SCT de la OMPI. La representación y la descripción de marcas no tradicionales. Posibles ámbitos de convergencia. En Comité Permanente sobre el Derecho de Marcas, Diseños Industriales e Indicaciones Geográficas. Décimonovena sesión. Ginebra: OMPI, 2008. 
SCT de la OMPI. Relación entre los principios existentes en materia de marcas y los nuevos tipos de marcas. En Comité Permanente sobre el Derecho de Marcas, Diseños Industriales e Indicaciones Geográficas. Décimoseptima sesión. Ginebra: OMPI, 2007.

sct de la OMPI. Nuevos tipos de marcas. En Comité Permanente sobre el Derecho de Marcas, Diseños Industriales e Indicaciones Geográficas. Décimosexta sesión. Ginebra: OMPI, 2006.

SIC. sic.gov.co. 28 de agosto de 2014. http://www.sic.gov.co/noticia/superindustriaconcedera-marcas-en-4-meses.

Soutol, Frank y Bresson, Jean-Philippe. Las marcas tridimencionales en la práctica francesa y comunitaria. Revista de la OMPI. Ginebra: OMPI (febrero de 2009). ISSN: 1020-7082.

Superintendencia de Industria y Comercio (sIC). Resolución sIC n. ${ }^{\circ} 33205$ del 27 de mayo de 2014.

Superintendencia de Industria y Comercio (sIC). Resolución n. ${ }^{\circ} 011956$, expediente n. ${ }^{\circ} 05-47635$, del 30 de abril de 2007.

Superintendencia de Industria y Comercio (sIC). Resolución n. ${ }^{\circ} 1765$, expediente n. ${ }^{\circ}$ 10-39538, del 26 de enero de 2011.

Superintendencia de Industria y Comercio (sIC). Concepto sic n. ${ }^{\circ}$ 30326, 2011. Superintendencia de Industria y Comercio (sIc). sic.gov.co. s. f. http://www.sic. gov.co/gaceta-oficial-de-la-propiedad-industrial

Supreme Court of the United States (scotus). Mishawaka Rubber \& Woolen Mfg. Co. v. S. S. Kresge Co. , 316 U.S. 203. 5 de mayo de 1942.

The United States Trademark Association (USTA). El manejo de las marcas comerciales, una guía para el hombre de negocios [Traducido del inglés por Brigard y Urrutia]. Nueva York: Ediciones Tercer Mundo, 1965.

Trademark Electronic Search System (TESS). s. f. http://tmsearch.uspto.gov/bin/ gate.exe? $\mathrm{f}=$ tess \&state $=4802: \mathrm{z} 15 \mathrm{le} 4.8 .1$.

Tribunal de Justicia de la Comunidad Andina. Proceso 28-IP-96. 31 de octubre de 1997.

Tribunal de Justicia de la Comunidad Andina. Proceso 15-IP. 27 de abril de 2011. Tribunal de Justicia de la Unión Europea (TJUE). Ralf Sieckmann v. Deutsches Patent-un Markenamt. C-273/00 del 6 de diciembre de 2002.

Tribunal de Justicia de la Unión Europea (TJUE). Philips v. Remington. C-299/99. 18 de junio de 2002.

Varela Pezzano, Eduardo. Manual de propiedad intelectual. Bogotá: Asociación Cavelier del Derecho, 2015. 